\title{
AN ANALYTIC HIERARCHY PROCESS BASED MODEL FOR THE SELECTION OF DECISION CATEGORIES IN MAINTENANCE SYSTEMS
}

\author{
Stefano lerace, Sergio Cavalieri \\ University of Bergamo, CELS - Department of Engineering, Italy \\ Corresponding author: \\ Stefano Ierace \\ University of Bergamo \\ Department of Engineering \\ Viale Marconi, Dalmine ( $B G)$, Italy \\ phone: +39(0)352052384 \\ e-mail: stefano.ierace@unibg.it
}

Received: 28 May 2013

Accepted: 12 June 2013

\begin{abstract}
This paper presents a model, based on Analytic Hierarchy Process, to support a maintenance manager with a suitable tool for focusing on the most relevant choices which need to be prioritized. The paper provides an insight on how structural and infra-structural decision elements, traditionally conceived for assessing the manufacturing strategy of a company, could be adopted as criteria for configuring a maintenance system. A model based on Analytic Hierarchy Process has been developed and tested in two industrial case studies in order to demonstrate how it can guide a maintenance manager in keeping the strategic decisions coherently with the overall company's manufacturing strategy.

Main beneficiaries are mainly maintenance managers who have to tackle relevant strategic decisions in managing their maintenance systems. Given the increasing role of maintenance within the operations strategy of a company, the heterogeneity of actors involved, with the relevant risk of assuming conflicting decisions, it is of utmost importance to lever on adequate and shared decision support systems rather than relying on a mere empirical knowledge. The model proposed in this paper, based on the Analytic Hierarchy Process, fills this gap since it provides a structured support in the decision making process by comparing and prioritising the relevant strategic decisions pertaining to the configuration of a maintenance system.
\end{abstract}

KEYWORDS

Decision categories, Analytic Hierarchy Process, Maintenance strategy, Case study.

\section{Introduction}

Today, world-class competitiveness is a must for companies. Globalisation of markets and more stringent requirements from customers put forward numerous challenges to managers. They strive to optimise all systems involved in their organizations in order to outperform on all the main Key Performance Indicators (KPIs). Maintenance as a system plays also a key role in achieving such organisational goals and objectives. According to a study carried out back in the eighties, the estimated cost of maintenance for a selected group of companies tripled in just 10 years. Moreover, with the invasive embedment of automation, robotics and computer-aided devices on production resources, maintenance costs were subjected to a further steep ascent increase [1]. The economic impact is not the only to be accounted for: maintenance plays also a significant role in providing high levels of availability of a piece of equipment or a machine, in ensuring outstanding product quality, not neglecting also safety requirements.

Unfortunately, unlike other operations management research streams, maintenance has received slight attention in the past. Mechefske and Wang [2] point out the following reasons: (i) traditionally, maintenance has been regarded as a necessary evil and, at best, as a system driven by production; (ii) maintenance in an organisation has complex relationships with other functions; and (iii) the output of maintenance is hard to measure and quantify. 
Moreover, as stated by [3], there is a growing need to explicitly capture the relationship, and to preserve a consistency, between the business strategy pursued by an industrial company and its maintenance system. Overlooking this relationship and focusing only on maintenance as a mere cost-cutting operative function can jeopardise the ability of a firm to compete in the market. From a literature analysis, despite a plethora of research contributions, minor attention has been devoted to the selection of the most suitable maintenance strategy for a given production environment.

Recalling a definition provided by [4], in this paper maintenance is considered in a broad perspective as "a set of components that work in a combined way towards a common objective. Maintenance can be considered to be a system with a set of activities that are realized in parallel with the production systems". As a result, building up a maintenance strategy cannot be scaled down to a decision upon the most convenient and effective maintenance policy to adopt for a specific plant or machine. Conversely, there is a multitude of heterogeneous decision variables to take into account. They, alike those traditionally conceived for establishing the operations strategy of a company, provide a response to the structural and infra-structural configuration of a maintenance system.

Aim of the paper is to provide a further insight on the way these strategic decisions need to be assessed in order to be aligned with the overall company's strategy and to preserve their internal consistency. As a base for the proposed model, the framework proposed by [5] for strategic manufacturing management has been considered, since more recent contributions have already provided its extension to the maintenance area [3]. Given also the need to adopt a model which could be easily and pragmatically used by industrial practitioners, a multi-criteria decision making tool based on the Analytic Hierarchic Process (AHP) technique has been developed. The model, and its developed tool, has been evaluated in two industrial case studies carried out in different manufacturing environments.

The remainder of the paper is organized as follows: Sec. 2 provides a literature review on maintenance management models, while Sec. 3 and 4 are devoted to an in-depth description of the AHP technique and of its application in the maintenance domain. Section 5 shows the application of an AHP model in two case studies, while Sec. 6 draws some conclusions, managerial implications and consideration for further research.

\section{Literature review on maintenance strategy}

In the past, maintenance has been regarded as a necessary evil within the overall production activity and as a technical issue without any impact on the business performance of a company and without the dignity to be managed as a strategic function. This cost-oriented perception has gradually evolved in the last years into a more distinguished role of maintenance as a key support process within the company's value chain which, in some cases, can even turn out into a primary profit-centered process [5].

As a result, also research in the maintenance area is flourishing. Several contributions have been carried out in order to define models for the selection of the most suitable maintenance strategy [6-9].

As aforementioned, in this paper the term maintenance strategy is viewed from the perspective of all the structural and infra-structural components pertaining to a maintenance system in lieu of a mere - albeit important as well - decision on the most suitable maintenance policies, in terms of $[10,11]$ :

- reactive or breakdown maintenance: equipment is allowed to run until failure; then the failed equipment is repaired or replaced;

- preventive maintenance: "maintenance carried out at predetermined intervals or corresponding to prescribed criteria and intended to reduce the probability of failure or performance degradation of an item";

- condition based maintenance: "maintenance carried out according to need as indicated by condition monitoring".

Literature in maintenance area shows two main approaches in selecting the suitable maintenance strategy [12]:

a) the so-called "Maintenance Management Model Oriented" in which maintenance is conceived in a broader perspective of a system;

b) the traditional "Maintenance Strategy Choice Oriented", in which maintenance is expressed in a narrow sense as a maintenance policy.

Hereafter these two approaches will be described highlighting their benefits and limits.

\section{Maintenance Management Model Oriented}

In this category of models maintenance is considered as a set of components that interplay towards a common objective. Campos and Crespo Marquez [12] provide an extended literature analysis on maintenance management models classifying them into declarative models and process oriented models. 
- Declarative management models: these models, mainly developed in the early ' $90 \mathrm{~s}$, provide a complete description of the main decisional elements characterising a maintenance management system [13-16]. However, there is no reference to any type of correlation and alignment between these elements. As a consequence, some functional aspects cannot be clearly appreciated. This is a major weakness of these models which limit their real applicability in an industrial company.

- Process oriented management models: they have been developed in the late ' 90 s and depict a clear flow of information (in terms of inputs and outputs) between the model components [7, 17-19]. However, they suffer from not being comprehensive in terms of description of all the aspects related to maintenance. In comparison with the previous one, this category of models is less exhaustive since they do not include all the components which may affect a maintenance system. Conversely, the possibility to consider the relationship between each of these factors makes these models more applicable in the industrial field.

\section{Maintenance Strategies Choices Oriented}

In this stream of literature contributions the term maintenance strategy is generally viewed from the perspective of maintenance policies. There is no attempt to describe a maintenance management model and its components. Emphasis is rather given to the definition of the most suitable maintenance policy among four main maintenance approaches (i.e. corrective, preventive, condition-based monitoring and predictive).

As Ierace and Cavalieri [20] pointed out, the selection of a maintenance policy can be regarded as a Multi Criteria Decision Method (MCDM) process, which encompasses several tangible and intangible (or not numerically quantifiable) factors.

These criteria can be classified into three main elements:

- failure based factors, which measure the impact of a failure (in terms of safety and costs) and the applicability of a maintenance approach;

- technology-based factors, which relate a maintenance policy to the installed production technology;

- business factors, which highlight the need to manage the maintenance department consistently with the overall corporate business strategy and in harmony with the other functions.
Literature related to the failure based approach is largely the most widespread in the maintenance area. Waeyenbergh and Pintelon [7] show a maintenance policy decision diagram, based on technical and economical questions, aiming at supporting a decision maker in assessing a maintenance strategy. Considering the literature related to technology-based factors, Swanson [21] tried to define the relationship between maintenance management and production technology. As an example of the tight intertwine between soft and hard factors, she demonstrates as advanced manufacturing technology and automation require a continuous training program for craft workers and supervisors to enhance their technical expertise. However, this approach does not take into account the impact of the severity of a failure and the role of the business environment on the maintenance strategy decision.

Finally, minor attention has been devoted to a comprehensive and in-depth analysis of the relationship between the business strategy of a company, its manufacturing decision categories and the role of maintenance strategy. According to authors' knowledge, only Pinjala et al. [3] try to fill this gap by conducting in their work a business-oriented empirical investigation. However, the resulting proposed model seems too general and does not provide the key elements which can pragmatically support a manager in taking maintenance decisions.

Table 1 shows a summary of the literature review considering the main drawbacks affecting each perspective.

There appears to be no contribution which provides an integrated framework able to establish a clear interrelation between the technical, organisational, managerial levers related to a maintenance system and their impact on the business and strategic KPIs of a company. This is due to the fact, that despite the numerous contributions on the technical and economical implications deriving from the adoption of specific maintenance choices, there is a lack of knowledge on the way to configure a maintenance system as a whole, in consistency with the abovementioned definition by [4].

As a result, maintenance is still relegated as a mere technical issue in which its business impact is underestimated. On the contrary, due to the utmost relevance of maintenance in managing industrial assets and the tighter investment opportunities, there is a compelling need in supporting a maintenance manager in prioritising the most effective decisions and evaluating beforehand their potential impact on the company's strategic KPIs. 
Table 1

Summary of the different perspectives in literature

\begin{tabular}{|c|c|c|c|}
\hline Perspective & Feature & Weaknesses & References \\
\hline \multirow{2}{*}{$\begin{array}{l}\text { Maintenance management } \\
\text { model oriented }\end{array}$} & Declarative & $\begin{array}{l}\text { Mention the component of a mainte- } \\
\text { nance system but do not consider any } \\
\text { functional elements }\end{array}$ & {$[13-16,22]$} \\
\hline & Process Oriented & $\begin{array}{l}\text { Depict a clear flow of information be- } \\
\text { tween the model components but do not } \\
\text { include all the components in mainte- } \\
\text { nance systems }\end{array}$ & {$[17,19,23-30]$} \\
\hline \multirow{3}{*}{$\begin{array}{l}\text { Maintenance strategy } \\
\text { choice oriented }\end{array}$} & Failure Based & $\begin{array}{l}\text { Focused only on maintenance policies } \\
\text { whose choice depends mainly on impact } \\
\text { of failure on production and safety }\end{array}$ & {$[2,6,9,20,31-33]$} \\
\hline & Technology Based & $\begin{array}{l}\text { Focused on the relationships between } \\
\text { production technology and mainte- } \\
\text { nance, neglecting the impact of failure } \\
\text { and the relationships with other func- } \\
\text { tions }\end{array}$ & {$[21]$} \\
\hline & Business Oriented & $\begin{array}{l}\text { Consider also business and manufactur- } \\
\text { ing strategies but do not include any } \\
\text { technical element }\end{array}$ & {$[3]$} \\
\hline
\end{tabular}

\section{Identifying Maintenance Decision Categories}

Which are the key decisions to be taken in a maintenance system and how to identify their mutual relationships? Though not omitting the specificity of maintenance, as an initial step it is possible to reason on analogy, by adapting some frameworks quite consolidated in the manufacturing strategy literature. It is worth mentioning the seminal work of Hayes et al. [34] who introduced ten structural and infra-structural decision categories that have been reported, reviewed and integrated in various successive works (e.g. [35-37]).

Among them, Pinjala et al. [3] have tried to extend the same logical structure for assessing a maintenance strategy. Table 2 summarizes the maintenance categories decision elements considering two groups, named structural and infra-structural, by adapting their work.

The first four decision elements are defined as structural because they are generally assumed as not changeable in the short and medium-term. For instance, a company, outsourcing its entire maintenance activities, cannot revert immediately to an in-house maintenance. This requires an adequate amount of time and capital investment to gather the necessary resources and skills. Similarly, the adoption of a predictive maintenance policy requires an initial capital investment for acquiring the required equipment, instruments and skills.

The infra-structural elements are generally linked to specific operational aspects of a company. As an example, with an increasing interdependency and au- tomation of equipment, companies tend to have a more decentralized maintenance organization structure [21]. Similarly, with the increasing relevance in maintenance technology (i.e. using of predictive and condition based maintenance) and in facilities (i.e. tools and spares supporting maintenance activities), nowadays companies tend to adopt Information Technology as a support for maintenance planning and control system (i.e. Computer Maintenance Management Systems, CMMS). This requires an investment more in the medium than in the long term and it is also interconnected with decisions made at a structural level such as, for example, those related to the selection of a maintenance policy.

It is evident the plurality of elements affecting maintenance decisions. In the attempt to build a model for supporting managers in keeping these decisions, the first step is to understand which are the interrelations between them. For example, if we refer to structural elements, as the maintenance "Capacity" (in terms of availability of resources), decisions taken on the infra-structural elements ("Human Resource") are related on how effectively these resources are utilized. Along with the recommendations from [3], structural decision elements may be considered as independent variables, since they are fixed and not changeable in the short and medium term. Conversely, infra-structural decision elements may be considered as dependent variables.

It is also evident how each decisional element presents a variety of alternative choices. They can exert a major impact on the ability of a maintenance function to implement and support the corporate business strategy. Given their interrelation, 
their eventual inconsistency can seriously jeopardise the effectiveness of any maintenance strategy.

As a consequence, a maintenance manager is overwhelmed with numerous and conflicting evaluations. He needs to rely on a model which could make evidence of these potential conflicting issues and finding a way to come to a compromise in a transparent process.

In any case, before discussing the relationships between these elements, it is important to assess how the highlighted elements represent the whole "pattern of decisions" to be taken in the maintenance domain. Neglecting this activity could seriously affect the effectiveness and the reliability of the model making it not exhaustive for a decision maker. The literature review provided in the previous section is instrumental for a critical review of the level of comprehensiveness of the elements listed in Table 2.

From the literature classification, the "Process Oriented" management models allow defining the input-output of each element in order to show the relationships between them. Among this category of models, it is here worth mentioning the contribution from [26], who identifies four strategic elements of maintenance: (i) service-delivery options: the choice between in-house capability and service outsourcing; (ii) organisation of the maintenance function and the way maintenance tasks are structured: this element is further split into an infra-structural element, named "Organisation", which designs the ar- chitecture (centralised or decentralised) of maintenance systems, and an infra-structural decision element named "Planning" which includes planning of maintenance activities (for instance spare parts control and location); (iii) maintenance methodology, which encompasses a structural decision element, termed "Technology" which defines the maintenance policy to be applied and the suitable maintenance policies mix for a plant, and an infra-structural decision element named "Maintenance Quality" related to the quality of maintenance interventions and the reliability of techniques used; (iv) design of the infrastructure that supports maintenance, including several decision categories, among which "Human Resources" (both in terms of skills and in terms of workforce capacity) as well as "Maintenance Planning Systems" (such as CMMS for spare parts control) and "Maintenance Performance Measurement".

Taking into account this model, it is possible to assume that the application of decision categories seems to be comprehensive of all the elements belonging to the maintenance field.

This is surely not sufficient since, for taking decisions which could impact positively on company's business strategy, also discovering the relationships between these elements is required. Hence, the next step, which will be discussed in the following paragraph, is to establish some criteria for managing these relationships.

Table 2

Decision categories applied in the maintenance domain (adapted from [3])

\begin{tabular}{|c|c|c|}
\hline & Categories & Decisions \\
\hline \multirow{4}{*}{$\begin{array}{l}\text { Structural } \\
\text { decision } \\
\text { elements }\end{array}$} & Capacity & $\begin{array}{l}\text { Capacity in terms of force, supervisory and management staff. Shift } \\
\text { patterns of work force, temporary hiring of work force }\end{array}$ \\
\hline & Facilities & $\begin{array}{l}\text { Tools, equipment, spares, workforce specialization (mechanics, elec- } \\
\text { tricians,... ) location of workforce }\end{array}$ \\
\hline & Technology & $\begin{array}{l}\text { Corrective, preventive or predictive maintenance, or condition moni- } \\
\text { toring technologies, maintenance technology (e.g. intelligent mainte- } \\
\text { nance) }\end{array}$ \\
\hline & Vertical integration & In-house maintenance vs outsourcing, relationship with supplier. \\
\hline \multirow{6}{*}{$\begin{array}{l}\text { Infra-structural } \\
\text { decision } \\
\text { elements }\end{array}$} & Organisation & $\begin{array}{l}\text { Organisation structure (centralized, de-centralized, or mixed), respon- } \\
\text { sibilities }\end{array}$ \\
\hline & $\begin{array}{l}\text { Maintenance } \\
\text { quality }\end{array}$ & $\begin{array}{l}\text { Quality of maintenance intervention and maintenance policy. Mainte- } \\
\text { nance engineering. Continuous improvement }\end{array}$ \\
\hline & Planning & $\begin{array}{l}\text { Maintenance activity planning, scheduling, control of spare costs. } \\
\text { CMMS }\end{array}$ \\
\hline & Human resource & $\begin{array}{l}\text { Recruitment policies, training and development of workforce and staff. } \\
\text { Culture and management style }\end{array}$ \\
\hline & Modifications & $\begin{array}{l}\text { Maintenance modifications, equipment design improvements, new } \\
\text { equipment installations and new machine design support }\end{array}$ \\
\hline & Performance measurement & Performance recognition, reporting and reward systems \\
\hline
\end{tabular}




\section{Analytic Hierarchy Process as a Multi Criteria Decision Method}

According to previous considerations, it is necessary to consider maintenance choice as a MultiCriteria Decision Method (MCDM) process. As the complexity increases, also the number of variables which should be considered increases. Therefore, similarly to what has been presented in literature review in which the selection of a maintenance policy depends on a plurality of variables, also the selection of the proper maintenance configuration system can be considered as a MCDM process in which independent variables influence the assessment of the most relevant dependent ones.

First of all, it is necessary to provide a definition of MCDM. According to [8] MCDM is a finite set of alternatives among which a decision-maker has to select or rank; a finite set of criteria weighted according to their importance. In addition, a decision matrix consists of the rating of each alternative with respect to each criterion using a suitable measure. The evaluation ratings are then aggregated taking into account the weights of the criteria, to get a global evaluation for each alternative and a total ranking of the alternatives. Summarizing, it is possible to consider MCDM as a discipline supporting decision makers in tackling numerous and sometimes conflicting evaluations. MCDM aims at highlighting these conflicts and deriving a way to come to a compromise in a transparent process. The application of MCDM encompasses several areas not only related to the engineering field. As a consequence, literature dealing with these techniques is wide and not related only to the maintenance area (for more information see [38]).

Among the most common techniques supporting the MCDM process, Analytic Hierarchy Process (AHP) [39] is a powerful and flexible multi-criteria decision making tool for complex problems where both qualitative and quantitative aspects need to be considered. It helps analysts to organise the critical aspects of a problem into a hierarchical structure similar to a family tree. AHP models an unstructured problem by decomposing it into a hierarchy of elements (usually, criteria and alternatives) influencing a system by incorporating levels, objectives, criteria, sub-criteria and alternatives. A pair wise comparison of elements in the hierarchy is made to determine the importance of each element and, ultimately, to estimate the relative score for each alternative. Thus, in effect, AHP attempts to analyse the impact of alternatives, or elements at the lowest level on the overall objective. AHP enables to structure a system and its environment into mutually interacting elements and then to synthesise them by measuring and ranking the impact of these elements on the whole system.

According to [40] AHP has the following advantages: (1) it is the only known MCDM model that can measure the consistency of decision makers' judgments; (2) it can help decision makers organize the critical aspects of a problem into a hierarchical structure; (3) pair wise comparisons in the AHP are often preferred by the decision makers, enabling them to derive weights of criteria and scores of alternatives from comparison matrices rather than quantify weights/scores directly.

The AHP involves the principles of decomposition, pair wise comparisons, and priority vector generation and synthesis. The procedure usually recommended for AHP is as follows:

a. Decompose the problem hierarchically, i.e., structure the problem in the following manner:

- Level 1: Overall objective / focus of the problem (goal of the problem);

- Level 2: Criteria used for evaluating the alternatives:

- Level 3: Sub-criteria

- Level n: set of decision alternatives to be evaluated with respect to the overall objective.

b. Compare pairs of elements in each level with respect to every element in the next higher level using Saaty's nine-point scale. The comparisons are entered in a pair wise comparison matrix. An element in the higher level governs the elements in the lower level. The pair wise comparisons are done in terms of which element dominates another. Following each "split" in the hierarchy, the importance of each attribute is compared, in turn, with every other attribute immediately below that "split".

A judgmental matrix, denoted as A, will be formed using the comparisons: each entry aij of the judgmental matrix is formed comparing the row element $A i$ with the column element $A j$ where aij is the relative importance of the criterion $i$ with respect to the criterion $j$.

The comparison of any two elements $A i$ and $A j$ with respect to the higher level element is made using questions of the type: "Of the two elements $A i$ and $A j$, which is more important with respect to the higher level element?".

Saaty suggests the use of a 9-point scale to transform the verbal judgements into numerical quantities representing the values of aij. The scale is explained in Table 3. The entries aij are governed by the following rules: 


$$
\begin{gathered}
a i j>0 ; \quad a i j=1 / a j i ; \quad \text { aii }=1 \\
\text { for } i, j=1,2, \ldots, n .
\end{gathered}
$$

Because of the above rules, the judgmental matrix $\mathrm{A}$ is a positive reciprocal pair wise comparison matrix.

c. After the matrix has been developed, the next step is to calculate a vector of priorities or weights of elements in the matrix A. In terms of matrix algebra, this consists of calculating, using the following formula, the "principal vector" $w$ (eigenvector) of the matrix, and then normalising it to sum to 1.0 or $100 \%$.

$$
A w=\lambda_{\max } w,
$$

where $\lambda_{\max }$ is the largest eigenvalue of the matrix $\mathrm{A}$ and the corresponding eigenvector $w$ contains only positive entries.

When the vector $w$ is normalized, it becomes the vector of priorities of the criteria with respect to the goal. The eigenvector for a consistent reciprocal square matrix can be obtained by normalization of any column vector of the matrix.

d. Once the priority vectors have been determined, it is then necessary to calculate the consistency ratio of the estimated vector.
The consistency of the judgmental matrix can be determined by a measure called the Consistency Ratio (CR), defined as:

$$
\mathrm{CR}=\frac{\mathrm{CI}}{\mathrm{RI}}
$$

where CI is called the Consistency Index and RI the Random Index.

CI is defined as:

$$
\mathrm{CI}=\frac{\lambda_{\max }-n}{n-1},
$$

$\mathrm{RI}$ is the CI of a randomly generated reciprocal matrix from the 9-point scale, with reciprocals forced. Saaty has provided average consistencies (RI values) of randomly generated matrices (up to size $11 \mathrm{x} 11$ ) for a sample size of 500 . These values, for matrices of different sizes $n$, are shown in Table 4

If the CR of the matrix is high, it means that the input judgements are not consistent, and hence are not reliable. In general, a CR of 0.10 or less is considered acceptable. If the value is higher, the judgements may not be reliable and have to be elicited again.

Table 3

The semantic scaled used in AHP (Saaty, 2004).

\begin{tabular}{c|c|l}
\hline Intensity of importance & \multicolumn{1}{|c}{ Definition } & Description \\
\hline 1 & Equal importance & Elements $A i$ and $A j$ are equally important \\
\hline 3 & Weak importance of $A i$ over $A j$ & Experience and judgement slightly favour $A i$ over $A j$ \\
\hline 5 & Essential or strong importance & Experience and judgement strongly favour $A i$ over $A j$ \\
\hline 7 & Demonstrated importance & Ai is very strongly favoured over $A j$ \\
\hline 9 & Intermediate & $\begin{array}{l}\text { The evidence favouring } A i \text { over } A j \text { is of the highest possible } \\
\text { order of affirmation }\end{array}$ \\
\hline $2,6,8$ & $\begin{array}{l}\text { When compromise is needed, values between two adjacent } \\
\text { judgements are used }\end{array}$ \\
\hline
\end{tabular}

Table 4

The average consistencies of random matrices (the Random Index values).

\begin{tabular}{c|c}
\hline $\mathrm{N}$ & $\mathrm{RI}$ \\
\hline 1 & 0.00 \\
\hline 2 & 0.00 \\
\hline 3 & 0.58 \\
\hline 4 & 0.90 \\
\hline 5 & 1.12 \\
\hline 6 & 1.24 \\
\hline 7 & 1.32 \\
\hline 8 & 1.41 \\
\hline 9 & 1.45 \\
\hline 10 & 1.49
\end{tabular}




\section{Applying the AHP based model in Maintenance Management}

Figure 1 shows the AHP model presented in this paper. As mentioned before, among several criteria based on MCDM, the use of AHP is here due mainly to the fact that AHP provides a ranking of the alternatives and not just the most important one. In addition, in industrial application, the pair-wise comparisons are preferred by a manager when several intangible criteria have to be treated.

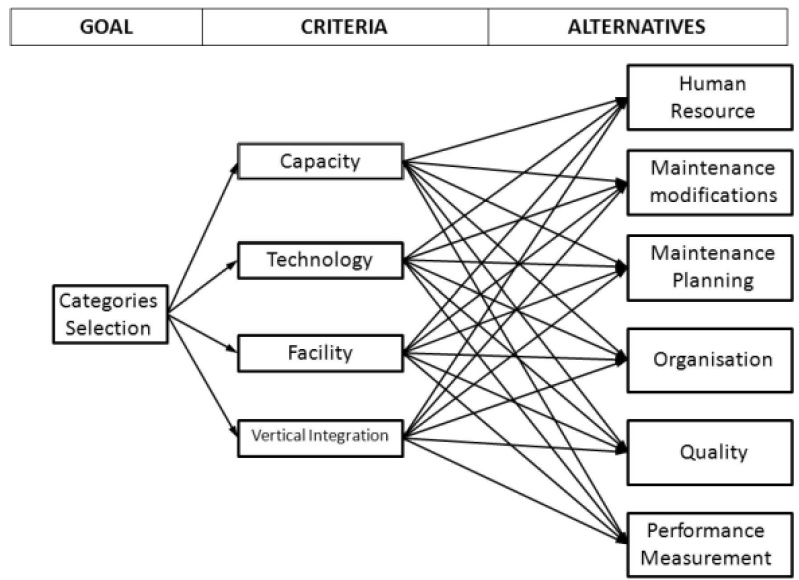

Fig. 1. The AHP model.

In designing the AHP hierarchical tree, the aim is to develop a general framework that satisfies the needs of the analysts to solve the selection problem of the most relevant decision elements. The AHP starts by breaking down a complex, multi-criteria problem into a hierarchy where each level comprises a few manageable elements.

The AHP hierarchy developed in this study is a three-level tree in which it is possible to point out:

- goal - represents the main objective of the model; in this case it aims at understanding the decision elements which better affect a maintenance strategy;

- criteria - which are the evaluation criteria that influence the primary goal; they are related to structural decision elements which are considered as independent variables, as before mentioned;

- alternatives - it comprises those infra-structural decision elements which are influenced by the structural decision categories.

After analysing the hierarchical structure of the problem, the second phase is split into two steps:

- weigh the criteria as a function of their importance for the goal;

- weigh the alternatives as a function of their importance for each criterion.
This allows the development of the judgment matrix, whose result shows the priority decisions for the maintenance manager [41].

\section{The case studies}

The AHP model has been tested in two companies belonging to different sectors for ascertaining its validity and real applicability to industry. Calling in mind the step by step procedure above described, from a practical perspective, after structuring the problem in a hierarchical way, it is necessary to weigh the elements in the AHP model.

More in detail, the weighing process consists of two main steps:

- weigh the criteria (structural decision categories) in relation with the goal: in this case maintenance managers (for both companies) develop their judgments for assessing, given the nature of the production system (manufacturing vs. process industry as an example) and the business strategies, which are the most relevant criteria (structural decision categories);

- weigh the alternatives (infra-structural decision categories) in respect with each criterion (structural decision categories); this step is very timeconsuming since decision makers have to develop a judgments matrix for each criterion. According to maintenance managers' knowledge, in this step they provide the way in which alternatives could exert influence on the criteria.

Hereafter, the application of the model in two real case studies is shown in order to assess its effectiveness as a supporting tool and to make evidence of the capability and level of comprehensiveness of the model.

\section{Case Study A}

The first case study has been carried out in a company producing braking systems for the automotive industry. From a manufacturing perspective, the plant is an aluminium foundry with an integrated cycle: from aluminium or aluminium alloys melting to heat treatment and finished product stock. The company mainly focuses on quality and innovation and the plant can be classified as capital intensive, where different technologies coexist with a strong influence on product quality.

The first step for the application of AHP is to understand which are the decisions taken as structural elements. The results for the specific case can be summarized as follows:

- Capacity: high maintenance capacity and specialization with high usage of outsourcing (in particular for planned plant stoppages); 
- Facility: decentralisation of workforce with a central maintenance engineering department responsible for maintenance activities planning;

- Technology: high adoption of preventive maintenance policies and use of Condition Based Maintenance $(\mathrm{CBM})$ techniques (in particular vibration analysis and thermography);

- Vertical Integration: partial, both in-house and outsourcing maintenance, with the last one limited for plant stoppages or not-core maintenance activities (e.g. facility management).

The AHP model has been developed in order to support the maintenance manager in defining which are the main priorities related to the infrastructural decisions to be taken into account.

This first case study reports the step-by-step procedure providing the practitioners the necessary support to apply this model. In the second case study it will be reported, for brevity, just the results of the procedure reached with the same steps here described.

1. Weigh the criteria (structural decision categories) in relation with the goal

The first step is related to the development of the matrix for providing the ranking of each criteria (structural decision categories) given the characteristics of the production system. Table 5 shows the resulting matrix; for example, the ratio Facility vs. Capacity is equal to 6.0 for the maintenance manager of this company. This means that the Facility is very relevant (see Saaty's scale: Table 3) and is more crucial than Capacity in his maintenance system.

The column "priorities" is the vector of priorities which represents the eigenvector of the matrix (note than the sum of the priorities is equal to 1). For the calculation of the eigenvector, MATLAB software has been used. The column "Ideal" provides the same results of the previous one: the difference is that here the most important categories have a value equal to 1 and, consequently, the other categories, have values less than one in the same proportion than before. At this point, it is possible to calculate the consisten- cy index (CI) among these decisions. As described previously:

$$
\mathrm{CI}=\frac{\lambda_{\max }-n}{n-1} \cong 0.09,
$$

where $\lambda_{\max }=$ maximum eigenvalue calculated by MATLAB software, $n=$ matrix order ( 4 in this case).

Since CI is less than 1 , it is possible to conclude that the decisions of the maintenance manager are consistent and then to continue with the following step.

2. Weigh the alternatives in respect with each criterion

This step is carried out with the same procedures developed in the previous one. A pair-wise comparison between infrastructural decision categories against each independent structural category for this specific case study has been carried out. In the following Table 6 the matrices and the relative consistency index are reported for each structural decision category (criteria).

After the calculation of each priority, the ranking of the alternatives (infrastructural decision categories) can be calculated with the following equation:

$$
P_{j}=\sum_{i=1}^{N} P_{j, i} \cdot w_{i},
$$

where $P_{j}$ - priority assigned to the alternative $j ; P_{j, i}$ - priority assigned to the alternative $j$ for the criteria $i ; w_{i}$ - priority assigned to the criteria i in respect to the goal.

The results of the process is summarised in Table 7 and depicted in Fig. 2 .

About the result of this process for Case Study A, it is possible to state that the main issue is related to maintenance planning: due to the high number of preventive maintenance and inspection activities, it is necessary to have a very accurate maintenance plan with a support of a Computerised Maintenance Management System (CMMS). Maintenance Quality is also fundamental due to the use of CBM techniques which have to be reliable in order to prevent and predict failure events.

Table 5

Reciprocal ranking of structural decision categories in Case A.

\begin{tabular}{l|c|c|c|c|c|c}
\hline & Capacity & Facility & Technology & $\begin{array}{c}\text { Vertical } \\
\text { Integration }\end{array}$ & Priorities & Ideal \\
\hline Capacity & 1.0 & 6.0 & 3.0 & 4.0 & 0.2805 & 0.4811 \\
\hline Facility & $1 / 6$ & 1.0 & 7.0 & 3.0 & 0.0863 & 0.1480 \\
\hline Technology & $1 / 3$ & $1 / 7$ & 1.0 & 9.0 & 0.5830 & 1.0000 \\
\hline Vertical Integration & $1 / 4$ & $1 / 3$ & $1 / 9$ & 1.0 & 0.0503 & 0.0862 \\
\hline
\end{tabular}


Management and Production Engineering Review

Table 6

Weighing alternatives with respect to each structural criterion.

\begin{tabular}{|c|c|c|c|c|c|c|c|c|}
\hline & $\begin{array}{c}\text { Human } \\
\text { Resource } \\
\end{array}$ & $\begin{array}{l}\text { Maintenance } \\
\text { modification }\end{array}$ & $\begin{array}{c}\text { Maintenance } \\
\text { planning }\end{array}$ & Organisation & $\begin{array}{c}\text { Performance } \\
\text { Measurement }\end{array}$ & Quality & Priorities & Ideal \\
\hline Human Resource & 1.0 & 2.0 & $1 / 4$ & $1 / 4$ & 3.0 & 4.0 & 0.129 & 0.365 \\
\hline Maintenance modifications & $1 / 2$ & 1.0 & $1 / 6$ & $1 / 6$ & 2.0 & 2.0 & 0.073 & 0.206 \\
\hline Maintenance planning & 4.0 & 6.0 & 1.0 & 1.0 & 5.0 & 6.0 & 0.353 & 1.000 \\
\hline Organisation & 4.0 & 6.0 & 1.0 & 1.0 & 5.0 & 5.0 & 0.344 & 0.975 \\
\hline Performance Measurement & $1 / 3$ & $1 / 2$ & $1 / 5$ & $1 / 5$ & 1.0 & $1 / 2$ & 0.047 & 0.132 \\
\hline Quality & $1 / 4$ & $1 / 2$ & $1 / 6$ & $1 / 5$ & 2.0 & 1.0 & 0.055 & 0.156 \\
\hline \multicolumn{9}{|c|}{ Alternatives's Weights with Respect to the Facility criterion Consistency index $=0.0561$} \\
\hline Human Resource & 1.0 & 3.0 & $1 / 6$ & $1 / 7$ & 2.0 & $1 / 3$ & 0.074 & 0.180 \\
\hline Maintenance modifications & $1 / 3$ & 1.0 & $1 / 5$ & $1 / 6$ & 2.0 & $1 / 3$ & 0.053 & 0.128 \\
\hline Maintenance planning & 6.0 & 5.0 & 1.0 & $1 / 2$ & 5.0 & 3.0 & 0.286 & 0.696 \\
\hline Organisation & 7.0 & 6.0 & 2.0 & 1.0 & 6.0 & 4.0 & 0.411 & 1.000 \\
\hline Performance Measurement & $1 / 2$ & $1 / 2$ & $1 / 5$ & $1 / 6$ & 1.0 & $1 / 3$ & 0.044 & 0.106 \\
\hline Quality & 3.0 & 3.0 & $1 / 3$ & $1 / 4$ & 3.0 & 1.0 & 0.133 & 0.323 \\
\hline
\end{tabular}

\begin{tabular}{|c|c|c|c|c|c|c|c|c|}
\hline \multicolumn{9}{|c|}{ Alternatives's Weights with Respect to the Facility criterion Consistency index $=0.0561$} \\
\hline Human Resource & 1.0 & 3.0 & $1 / 6$ & $1 / 7$ & 2.0 & $1 / 3$ & 0.074 & 0.180 \\
\hline Maintenance modifications & $1 / 3$ & 1.0 & $1 / 5$ & $1 / 6$ & 2.0 & $1 / 3$ & 0.053 & 0.128 \\
\hline Maintenance planning & 6.0 & 5.0 & 1.0 & $1 / 2$ & 5.0 & 3.0 & 0.286 & 0.696 \\
\hline Organisation 7.0 & 6.0 & 2.0 & 1.0 & 6.0 & 4.0 & 0.411 & 1.000 & \\
\hline Performance Measurement & $1 / 2$ & $1 / 2$ & $1 / 5$ & $1 / 6$ & 1.0 & $1 / 3$ & 0.044 & 0.106 \\
\hline Quality & 3.0 & 3.0 & $1 / 3$ & $1 / 4$ & 3.0 & 1.0 & 0.133 & 0.323 \\
\hline \multicolumn{9}{|c|}{ Alternatives's Weights with Respect to the Technology criterion Consistency index $=0.09$} \\
\hline Human Resource & 1.0 & 3.0 & $1 / 5$ & $1 / 3$ & $1 / 3$ & $1 / 7$ & 0.056 & 0.138 \\
\hline Maintenance modifications & $1 / 3$ & 1.0 & $1 / 5$ & $1 / 3$ & $1 / 2$ & $1 / 5$ & 0.043 & 0.105 \\
\hline Maintenance planning & 5.0 & 5.0 & 1.0 & 4.0 & 7.0 & $1 / 2$ & 0.303 & 0.749 \\
\hline Organisation & 3.0 & 3.0 & $1 / 4$ & 1.0 & 3.0 & $1 / 5$ & 0.121 & 0.298 \\
\hline Performance Measurement & 3.0 & 2.0 & $1 / 7$ & $1 / 3$ & 1.0 & $1 / 6$ & 0.073 & 0.180 \\
\hline Quality & 7.0 & 5.0 & 2.0 & 5.0 & 6.0 & 1.0 & 0.405 & 1.000 \\
\hline
\end{tabular}

Table 7

Priorities for each alternative.

\begin{tabular}{l|c|c}
\hline & Priorities & Ideal \\
\hline Human Resource & 0.095 & 0.308 \\
\hline Maintenance modifications & 0.052 & 0.168 \\
\hline Maintenance planning & 0.308 & 1.000 \\
\hline Organisation & 0.215 & 0.699 \\
\hline Performance Measurement & 0.062 & 0.200 \\
\hline Quality & 0.268 & 0.870 \\
\hline
\end{tabular}

Alternatives's Weights

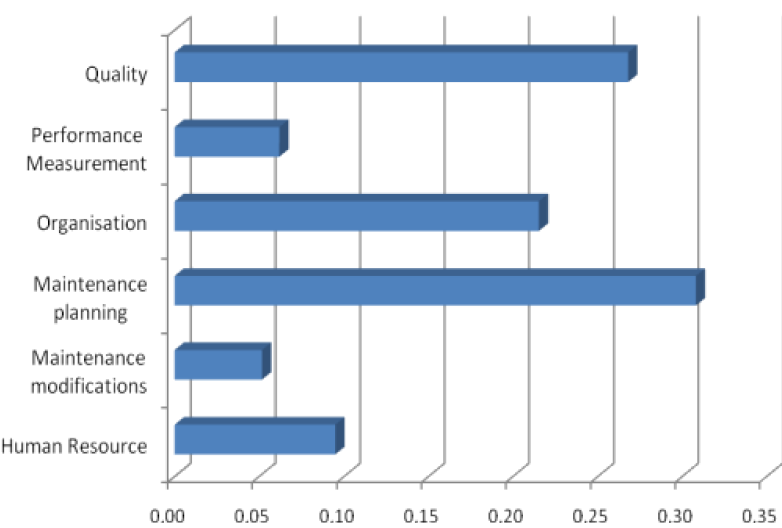

Fig. 2. The most relevant infra-structural decision elements in Case Study A. 


\section{Case Study B}

The second case study is related to a company operating in the textile industry and producing fashion garments, whose main competitive success factors are outstanding quality and high level of innovation. The model has been applied to two different plants in order to evaluate whether different maintenance choices are needed in the same company. The procedure here developed is the same that this one showed in Case Study A. As a consequence, for brevity, it is here analysed only the results of the process.

The first plant manufactures weaving and dyeing yarn. It is a typical job-shop producing small quantities of a large numbers of different products. Therefore, the degree of automation is low with high human intervention in process. It presents the following features about structural decision choices:

- Capacity: low maintenance capacity with low usage of outsourcing;

- Facilities: location centralized and workforce classified for mechanical and electrical specialization;

- Technology: corrective maintenance with low usage of a preventive approach;

- Vertical Integration: in-house maintenance.

Analogously with the previous case study, pair wise judgements have been developed in collaboration with the maintenance manager and maintenance staff. The results are shown in Fig. 3.

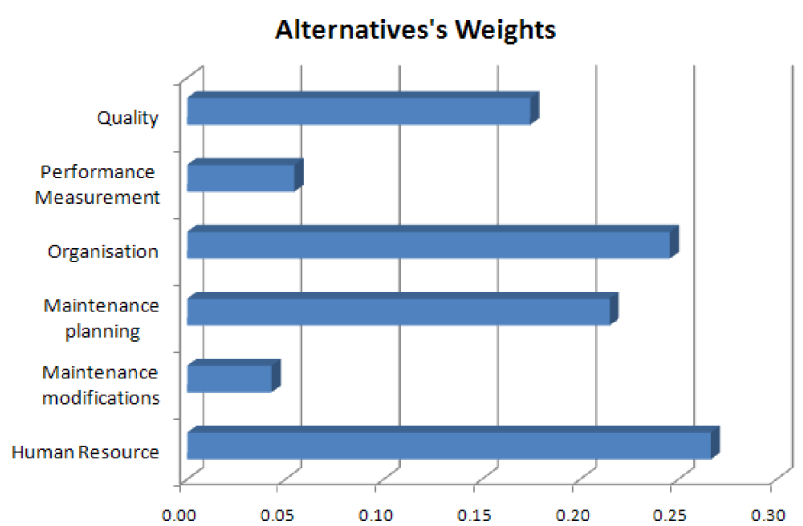

Fig. 3. The most relevant infrastructural decision elements in Case Study B (first plant).

In this scenario, human resources and organization are the two main elements to be considered. Human resources need to be skilled since they have to perform maintenance activities to all the machines within the plant (low usage of maintenance outsourcing) and, as a consequence, they need to have an internal organization for defining roles and responsibilities. In addition, maintenance planning is an important activity since it is necessary to have a tight control of spare part inventory due to the high usage of the corrective approach.

Unlike the first plant, the second one is devoted to drying, curing and finishing of woven and knitted fabrics. This final operation is needed to extend the fabric woven for restoring the original dimensions that have been shrunk in the previous working phases, applied to the fabric in order to provide it with particular characteristics, such as stiffness, water proofing, and so on. The production cycle in this case is much simpler than for the first plant (flow line vs. job shop). The plant can be classified as capital intensive with low human intervention.

With regards to the structural decision categories, they present the following features:

- Capacity: high maintenance capacity and specialization with high usage of outsourcing;

- Facilities: location decentralised with a high specialization and some centralised functions such as condition monitoring, maintenance reporting and maintenance engineering;

- Technology: vast adoption of predictive maintenance;

- Vertical Integration: high adoption of outsourcing. In this case, it is possible to state that the main issue is related to the planning of maintenance activities and the quality of maintenance intervention (Fig. 4). This is due to the fact that there are numerous inspections to be planned and therefore also maintenance organization becomes an utmost issue to be considered. In addition, the high use of predictive maintenance requires the need to rely on sound predictive techniques and, as for the first case study, quality is one of the main decisions to take into account.

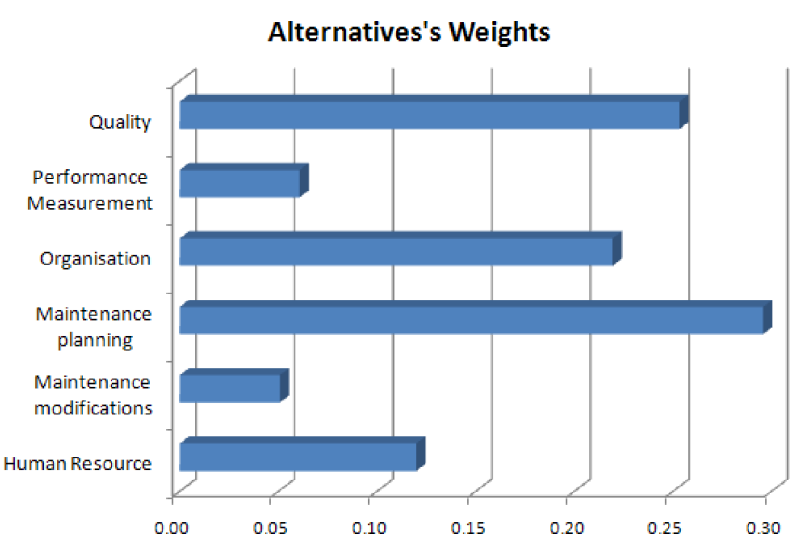

Fig. 4. The most relevant infra-structural decision elements in Case Study B (second plant).

This second sub-case is comparable to case study A, since the structural elements and the production technology are very similar. 


\section{Conclusions and managerial implications}

After having analysed the development of the maintenance concept and performed a literature review in the maintenance area, the paper focuses on the concept of decision categories in order to clarify which patterns of strategic decisions a maintenance manager has to assign more relevance to.

A definition of maintenance decision categories, traditionally applied in the manufacturing area, is provided and a model, based on the AHP technique, has been proposed in order to support companies in aligning their maintenance decision choices.

The model has been evaluated in two different companies highlighting the relationships between the infrastructural and structural decision categories. It also provides a tool which can be easily used by industrial practitioners to prioritise their actions.

In particular, in the second case study, related to two different plants with different manufacturing characteristics, it came out that also the relevance on maintenance decision categories could be dissimilar even within the same company. This outcome puts emphasis on the role of technology on maintenance decisions. As suggested by [21], maintenance strategy cannot be derived considering only the business strategy or the competitive priorities of a company, but taking into considerations also some technical factors, as the production technology or productrelated determinants.

From the analysis conducted it is evident that each decision category can play a different significance according to the specific industrial case. The proposed model attempts to support a maintenance manager with a suitable tool for focusing on the most relevant choices which need to be prioritised.

A further enhancement of the model is needed in future works in order to assess which are the main elements that influence a decision. In fact, a limit of the model is that, though enabling the prioritisation of the most relevant decisions (related to the infra-structural elements), it does not provide any help for undertaking them. As a consequence, a future step is needed for an extension of the model in order to provide the manager with an advice on the most suitable choice for each selected specific decision category.

Finally, by making use of the same model, an integrated performance measurement system could be developed in order to periodically monitor the efficiency and effectiveness of the undertaken decisions.

\section{References}

[1] Blanchard S.B., An enhanced approach for implementing total productive maintenance in the manufacturing environment, Journal of Quality in Maintenance Engineering, 3, 2, 69-80, 1997.

[2] Mechefske C.K., Wang Z., Using fuzzy linguistic to select optimum maintenance and condition monitoring strategies, Mechanical Systems and Signal Processing, 17, 2, 305-316, 2003.

[3] Pinjala S.K., Pintelon L., Vereecke A., An empirical investigation on the relationship between business and maintenance strategies, International Journal Production Economics, 104, 214-229, 2006.

[4] Duffuaa S., Raouf A., Dixon Campbell J., Sistemas de mantenimiento. Planeación y control, Limusa, México, 2000.

[5] Pintelon L., Gelders L., VanPuyvelde F., Maintenance Management, second ed. Belgium, Leuven, 2000.

[6] Bevilacqua M., Braglia M., The analytic hierarchy process applied to maintenance strategy selection, Reliability Engineering and System Safety, 70, 7183, 2000.

[7] Waeyenbergh G., Pintelon L., A framework for maintenance concept development, International Journal of Production Economics, 77, 299-313, 2002.

[8] Al-Najjar B., Alsyouf I., Selecting the most efficient maintenance approach using fuzzy multiple criteria decision making, International Journal of Production Economics, 84, 85-100, 2003.

[9] Wang L., Chu J., Wu J., Selection of optimum maintenance strategies based on a fuzzy analytic hierarchy process, International journal of Production Economics, 107, 151-163, 2007.

[10] Swanson L., Linking maintenance strategies to performance, International Journal of Production Economics, 70, 237-244, 2001.

[11] British Standard, British Standard Glossary of Maintenance Management Terms in Terotechnology, British Standard Institution, London, 1984.

[12] Campos M.L., Crespo Márquez A., Review, Classification and Comparative Analysis of Maintenance Management Models, In: Proceedings of 9th IFAC Workshop on Intelligent Manufacturing Systems, October 9-10, 2008, Szczecin, Poland, pp. 339-344, 2008.

[13] Pintelon L., Van Wassenhove L., A maintenance management tool, Omega, 18, 1, 59-70, 1990. 
[14] Pintelon L., Gelders L.F., Maintenance Management Decision Making, European Journal of Operational Research, 58, 301-317, 1992.

[15] Cholasuke C., Bhardwa R., Antony J., The status of maintenance management in UK manufacturing organisations: results from a pilot survey, Journal of Quality in Maintenance Engineering, 10, 1, 2004.

[16] Tam A., Price J., Beveridge A., A maintenance optimisation framework in application to optimise power station boiler pressure parts maintenance, Journal of Quality in Maintenance Engineering, 13, 4, 364-384, 2007.

[17] Vanneste S.G., Van Wassenhove L.N., An integrated and structured approach to improve maintenance, European Journal of Operational Research, 82, 2, 241-257, 1995.

[18] Söderholm P., Holmgren M., Klefsjö B., A process view of maintenance and its stakeholders, Journal of Quality in Maintenance Engineering, 13, 1, 19-32, 2007.

[19] Crespo Márquez A., The Maintenance Management Framework. Models and Methods for Complex Systems Maintenance, Springer, United Kingdom, 2007.

[20] Ierace S., Cavalieri S., Maintenance Strategy Selection: a comparison between Fuzzy Logic and Analytic Hierarchy Process, In: Proceedings of 9th IFAC Workshop on Intelligent Manufacturing Systems, October 9-10, 2008, Szczecin, Poland, pp. 327-332.

[21] Swanson L., An empirical study on the relationship between production technology and maintenance management, International Journal of Production Economics, 53, 191-207, 1997.

[22] Prasad Mishra R., Anand D., Kodali R., Development of a framework for world-class maintenance systems, Journal of Advanced Manufacturing Systems, 5, 2, 141-165, 2006.

[23] Riis J., Luxhoj J., Uffe T., A situational maintenance model, International Journal of Quality and Reliability Management, 14, 4, 349-366, 1997.

[24] Wireman T., World Class Maintenance Management, Industrial Press, New York, 1990.

[25] Hassanain M.A., Froese T.M., Vanier D.J., Development of a maintenance management model based on IAI standards, Artificial Intelligence in Engineering, 15, 1, 177-193, 2001.

[26] Tsang A., Strategic dimensions of maintenance management, Journal of Quality in Maintenance Engineering, 8, 1, 7-39, 2002.

[27] Murthy D.N.P., Atrens A., Eccleston J.A., Strategic maintenance management, Journal of Quality in Maintenance Engineering, 8, 4, 287-305, 2002.
[28] Abudayyeh O., Khan T., Yehia S., Randolph D., The design and implementation of a maintenance information model for rural municipalities, Advances in Engineering Software, 36, 8, 540-548, 2005 .

[29] Pramod V.R., Devadasan S.R., Muthu S., Jagathyraj V.P., Dhakshina Moorthy G., Integrating TPM and QFD for improving quality in maintenance engineering, Journal of Quality in Maintenance Engineering, 12, 2, 1355-2511, 2006.

[30] Kelly A., Maintenance and the industrial organization in Strategic Maintenance Planning, Butterworth-Heinemann, United Kingdom, 2006.

[31] Sharma R.K., Kumar D., Kumar P., FLM to select suitable maintenance strategy in process industries using MISO model, Journal of Quality in Maintenance Engineering, 11, 4, 359-374, 2005.

[32] Luce S., Choice criteria in conditional preventive maintenance, Mechanical Systems and Signal Processing, 13, 1, 163-168, 1999.

[33] Okumura S., Okino N., A maintenance policy selection method for a critical single-unit item in each workstation composing a FMS with CBM optimisation, International Journal of COMADEM, 6, 2, 3-9, 2003.

[34] Hayes R.H., Wheelwright S.C., Clark K.B., Dynamic Manufacturing: Creating the Learning Organization, The Free Press, New York, 1984.

[35] Mill J., Neely A., Platts K., Gregory M., Creating a Winning Business Formula, Cambridge University Press, Cambridge, 2002.

[36] Goetschalckx M., Vidal C.J., Dogan K., Modeling and design of global logistics systems: A review of integrated strategic and tactical models and design algorithms, European Journal of Operational Research, 143, 1, 1-18, 2002.

[37] Hallgren M., Olhager J., Quantification in manufacturing strategy: A methodology and illustration, International Journal Production Economics, 104, 113-124, 2005.

[38] Scholz R.W., Tietje O., Embedded Case Study Methods. Integrating Quantitative and Qualitative Knowledge, Sage Publications, Thousand Oaks, Sage, ISBN 0761919465, 2002.

[39] Saaty T.L., The analytic hierarchy process, McGraw-Hill, New York, 1980.

[40] Triantaphyllou E., Kovalerchuk B., Mann L., Knapp G.M., Determining the most important criteria in maintenance decision making, Journal of Quality in Maintenance Engineering, 3, 1, 16-28, 1997.

[41] Deng H., Multicriteria analysis with fuzzy pairwise comparison, International Journal of Approximate Reasoning, 21, 215-231, 1999. 